\title{
Ueber den Kaffee;
}

\section{von Robiquet und Boutron.}

Die Verf. unteraubmen diese Arbeit in der Absicht, in dem Katlee ein eigenthümliches Princip zu linden, welches demselhen seine so augezeichuete Wirkung anf die thierische Oekonomie rerlaiht.

Die hauptsächlichsteu Thatachen dieser Arbeit sind folgende: die grünen Bounen eatbalten rin durch Aether ausriehbares, freies $\mathrm{Ocl}$ in riemlicher Quantität, welehes mit Allialien eine barte Seife liefert, die sieh durch Einwirkung des Alkalis auf eincn darin enthaltenen Farbstoff rothibraun firlt. Dieses Oel, welches angefăbr $\mathbf{Q}$ Uazen aufs Pfund beträgt, ist nur in dem Innern der Bohnen enthalten, während die äussere Oberfäebe mit vegetobilischem Wachse uberzogen ist. Jer Kaffee entbält eine Lleine Quantitat Sebrefel; dann einen Farbetof und eine Säure, wahrseheialich Graliussïure, is sie sebr empfiudlich auf Eisenoxydsalue reagirt. Der Farbatuf und diese Säure sind sehr innigy mit einander perbunden, so dass sie schwierig für sich darzustellen sind.

Beim Rösten des liaffees entwickelt sich nor $W$ asser, Essigsäure und ein zuerst angenehun riechendes, bei fortschreitender Kïstung aber scharfes und unangenehm riechendes empyreumatisches $\mathrm{Oel}$, und gegen Ende sublimirce lange Fäden von Killein. Aetber zieht aus dem gerösteten liaffee eir braunes, mil dem aromatischen Principe des Kaffees sehr Laladenes, fettes Oel.

Das Kaffein finciet sich in allen Producten des Raffees, welcher Behandlungsweise man ilun auch unterwerfen magDieses Princip ist sehr weniz veränderlich; es widerstebt der serstörendes Einwirkung lor Faulnigs und der hohen 
Temperatur des Rästens. Es zeigte selbst dann nicht die geringste Veründerung, nachdem es einige Monate lang der Einwirkung des Wassers and der Luft nusgesetzt war. Bie Verf. sind geneigt, diesem Producte die wesentlichen Eigenschaften des Faffees zuzuschreiben; es ist nicht alloin stickstoffhultig- wie die meisten wirlisamen Hestandtheile der Vegetabilien, sondern es hildet allch wie diest mit Gerbstofi eine mlüsliche Verbinding. Diese Eigenschaft benitzten die Verf, um das Kaffein auszuriphen. Es wurdea 300 Grammea Kaffec leicht geröstet, und das Pulver aweimal in awei Liter Wasser go Minuten lang gekocht. Dic durchgeseihten Abkochungeu röthetes Lacmus; man sät igt sie mit einigen Tropfen Aetanatron ural rigt nun ein otarkes Gallüpfeldecoct hinza. Es entsteht pia reichlicher Nitulerschlag, der hald bäsig ist und sich leieht zu Bodra setat, bald in der Flissigkeit suspendirt bleiht. In letzteren Fall muss man, je uach dem Sïttigungrzasfand der Flüssiglieit, entweder etwas Aetznatron oder verdionute Schwefelszure ausetzen, um dis Coagulation des Präcipitats zu veranlassen.

Man bringt cun alles ant tine diebte Leinovoul, zerreibt den Nicterschlacy. nach dem Abtröpfeln, mit i0 Granmen an der Luft zeriallenen Kalkes, und kocht mit Alkounl von $35^{\circ}$ wielerbolt ans. Man deslillirt den Weingeist ab, und verdampft deu liuekstand woch in einor Schale bei gelindur Wïrue. Beiw Erkalten erbät man unehr odes veniger dunkelgrünlici gefirbite Krystalle, welehe aher durch nochnaliges Umbrysiallisiren ganc rein werden.

Bin rorzüglichsten finfecsorton wurlen dieser Behandlugg unterworfen und liafertes auf 500 Grm. diver jeden, folgcide Verhiituisse: 
Cup and Soubeiran. Hiber Blusentafiet.

Caffein.

Gram. Gran.

\begin{tabular}{|c|c|c|}
\hline liafiee & von Martinigue & 1,78 \\
\hline . & "Alexandrien & 1,26 \\
\hline$p$ & - Sava & 1,20 \\
\hline 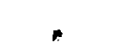 & - Molika & 1.06 \\
\hline " & " Cayeane & 1.00 \\
\hline D & st. Womingo & 0,83 \\
\hline
\end{tabular}

(Journal de Pharmacie Mar* $1837 \mathrm{~S}$ 101,)

Bericht über eine Vorschurit zu blasenziehendem Taffet des Hrn. Deschamps; von Cap und Soubeirau.

In dern Codex findet man eine Vorschrift zu blasen. aiehendem Taffet ron $G$ uilbert, nach welcher Seidelbast, Canthariden, Euphurbium und Myrhe uit Wasser ge. koch1, and dieses concentrirtc Decoct wittelst eine\& Pinsels auf Taftet nusgebreitet wiral.

Nur Wenige befolite" liese Varscbrift, denn der Tafint schuppt sich hald nach der Bereitung leicht ab. Im Jahre 1613 machte Hr. Orou ot eine andere, bessere Vorsehrift bekannt; sie bestebt aus den mit Essigalher verferligten Tiucturen ron Seidellast und Canthariden, in welehen etwas Colophonium aufgelöst ist, und welehe auf Gnmmi-Taffet aufyestrichen werden. Die Güte der 